\title{
Idiopathic reversible cerebral vasoconstriction syndrome (RCVS)
}

\author{
Tarig Mohammed Abkur, Mamoun Saeed, Nidal Osman Alfaki, Margaret O'Connor
}

Department of Internal Medicine, University Hospital Limerick, Limerick, Ireland

\section{Correspondence to} Dr Tarig Mohammed Abkur tarig1982@hotmail.com

Accepted 28 September 2014

\section{SUMMARY}

Reversible cerebral vasoconstriction syndrome is characterised by severe thunderclap headache with associated characteristic transient, multifocal, segmental vasoconstriction of cerebral arteries lasting several weeks to months. We describe a 50-years old woman who presented with a severe sudden onset occipital headache. Neuroimaging revealed segmental vasospasm affecting the intracerebral arteries. The pain improved gradually over the next 6 weeks. Repeat brain MR angiography at 12 weeks showed complete resolution of the segmental narrowing.

\section{BACKGROUND}

Reversible cerebral vasoconstriction syndrome (RCVS) (Call-Fleming syndrome) is a poorly understood disease in which the arteries of the brain undergo transient vasoconstriction that could last for up to 3 months. It is a retrospective diagnosis as it requires repeat imaging to demonstrate the resolution of the cerebral arterial spasm. The condition remains under-recognised. The treatment of RCVS is based on observational studies, randomised controlled trials do not exist yet.

\section{CASE PRESENTATION}

A previously healthy 50 years old woman presented to our facility after she had experienced four episodes of thunderclap headache. She described a sudden onset, occipital, severe headache. The headache was associated with vomiting. She reported worsening of the headache by straining and lifting objects. The pain affected the occipital area with minimal spread to temporal area bilaterally and lasted for up to $2 \mathrm{~h}$ on each occasion. The episodes were several days apart. She found no relief from paracetamol. She denied any confusion, fever, visual symptoms or seizures.

The patient was not on any regular medication and denied any illicit drug use.

Physical examination revealed Glasgow Coma Scale (GCS) of 15 . Her vital signs were as follows: temperature, $36^{\circ} \mathrm{C}$; blood pressure, $160 / 90$; pulse, $85 \mathrm{bpm}$. Detailed neurological examination did not show any focal deficit. There was no neck stiffness or other signs of meningeal irritation.

\section{INVESTIGATIONS}

Initial laboratory studies were unremarkable including normal white cell count, erythrocyte sedimentation rate and $\mathrm{C}$ reactive protein. Urgent CT of the brain did not show any abnormality. Cerebrospinal fluid (CSF) analysis showed no white or red blood

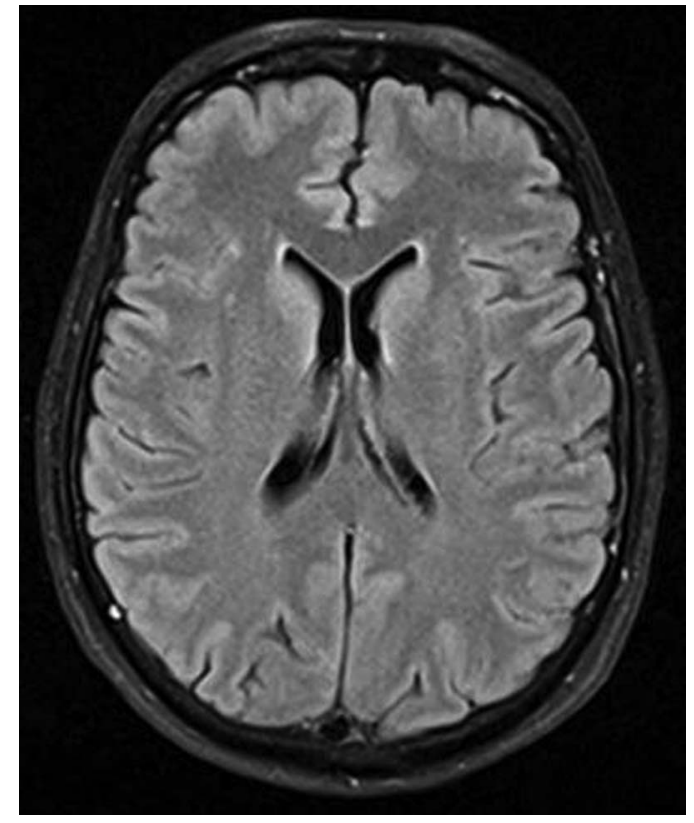

Figure $1 \mathrm{MRI}$ of the brain demonstrating normal structures.

cells, and normal chemistry. Xanthochromia and microbiology studies were negative. MRI of the brain was unremarkable (figure 1). MRA showed focal narrowing in intracerebral arteries (figure $2 \mathrm{~A}, \mathrm{~B}$ ).

\section{DIFFERENTIAL DIAGNOSIS}

- Primary angiitis of the central nervous system (PACNS).

- Aneurysmal subarachnoid haemmorhage with vasospasm.

- Intracerebral atherosclerosis.

\section{TREATMENT}

The symptoms were treated conservatively with bed rest and analgesia.

\section{OUTCOME AND FOLLOW-UP}

The headache gradually resolved over the next 6 weeks. Repeat brain MR angiography (MRA) at 12 weeks showed complete resolution of the vasospasm (figure 3).

\section{DISCUSSION}

The actual prevalence of RCVS is unknown. The disease predominantly affects individuals between 20 and 50 years of age. ${ }^{1-4}$ However, children can be affected as well. In the literature there are five cases 

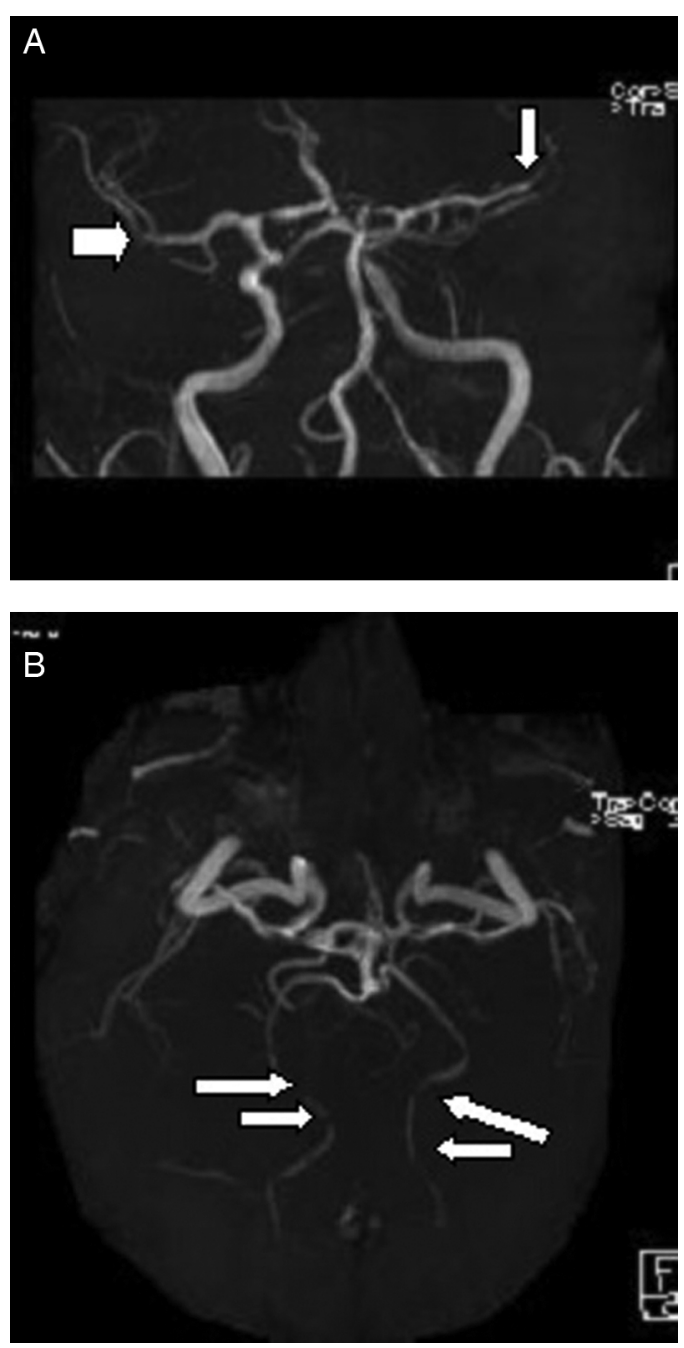

Figure 2 (A) MR angiography (MRA) of the brain showing multifocal segmental spasm. (B) MRA of the brain showing multifocal segmental spasm.

of RCVS in the paediatrics population, all of them were men. ${ }^{5-7}$ RCVS occurs more commonly in women than men with female to male ratios ranging from $2.6: 1$ to $10: 1 .^{38}$ The female preponderance appears to be less significant in secondary forms of RCVS. The exact pathogenesis of RCVS remains unclear; however, sympathetic over activity may have a role to play.

The disease can be either spontaneous or precipitated by several factors. Vasoactive drugs and the postpartum period are

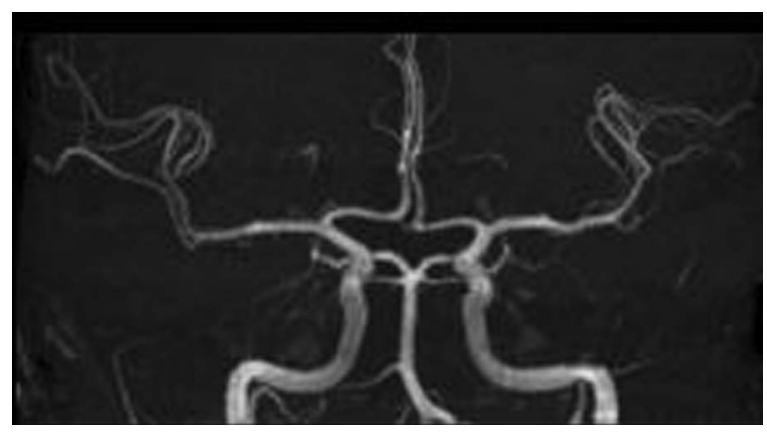

Figure 3 Repeat MR angiography of the brain at 12 weeks showing complete resolution of the vasospasm. two common associations. ${ }^{4}$ The disease has also been linked to the use of immunosuppressant and cytotoxic drugs. The spontaneous cases account for approximately one-third of patients, and precipitating factor can be identified in the remaining two-thirds. ${ }^{3}$

Studies have shown that thunderclap headache is the only presenting symptom in $76-85 \%$ of patients. ${ }^{3}{ }^{4}$ The headache tends to be recurrent in up to $94-100 \%$ of patients, and they are the most important clinical feature of RCVS. ${ }^{3}$ The headache may occur spontaneously or provoked by exercise. Valsalva manoeuvres tend to exacerbate the pain. Nausea, vomiting, confusion, blurred vision and transient hypertension often accompany the headache. Focal neurological deficits were present initially in $43 \%$ and generalised tonic-clonic seizures occurred in $17 \% .^{4}$

Digital subtraction angiography is the gold standard investigation. ${ }^{2}$ However, it is invasive and not practical for frequent imaging which may be required to assess for reversibility of the vasospasm. ${ }^{9}$ Additionally, transient neurological deficits occurred in $9 \%$ of patients following catheter angiography in one large study. ${ }^{3}$ MRA is an acceptable alternative for evaluation of the vasoconstriction in patients with RCVS. CT angiogram (CTA) can also be used to assess the intracerebral vessels but the exposure to radiation limits its use.

The CSF is usually normal, but it may show slight abnormalities such as pleocytosis of up to 15 nucleated cells, small numbers of red cells and/or minimally increased protein level. ${ }^{3}$

Transcranial Doppler ultrasound may be used to predict which patients will develop ischaemic complications after RCVS diagnosis is performed. It has good potential in monitoring larger vessel vasospasm. Mean flow velocity of the middle cerebral artery (MCA) more than $120 \mathrm{~m} / \mathrm{s}$ was associated with increased risk of ischaemic complications. ${ }^{10}$

In the French cohort, the incidence of subarachnoid haemorrhage (SAH) that complicates RCVS was found to be $22 \%$. These SAHs tend to be superficial, multiple, short segmental with disproportionate wide-spread vasoconstriction. On the contrary, SAH-induced vasospasm is more commonly long segmental and mainly around the bleeding focus. ${ }^{11}$

Other complications include intracerebral haemorrhage (6\%), posterior reversible leukoencephalopathy (9\%), transient ischaemic attack (TIA) (16\%) and cerebral infarction (4\%), often in the watershed areas. The haemorrhagic events tend to occur during the first week while the ischaemic complications take place later during the second week. The follow-up series of the French cohort described $34 \%$ incidence of intracerebral haemorrhage. $^{12}$

A recent study showed that about $12 \%$ of patients with RCVS also had an associated cervical artery dissection. As a consequence, systematic imaging of the cervical carotid and vertebral arteries is necessary in patients with RCVS. ${ }^{13}$

RCVS shares the same angiographic appearance with PACNS and the differentiation between the two entities can be very challenging. Patients with PACNS present with a history of dull headaches, usually have an insidious course of progressive neurological deterioration in contrast to RCVS which present with acute headache and is usually self-limited disease. CSF analysis usually demonstrates inflammatory changes in cases of PACNS with elevated protein above $100 \mathrm{mg} / \mathrm{dL}$ and leucocytosis; however, none of these findings is specific for PACNS. ${ }^{14-16}$ The sensitivity of brain biopsy for PACNS is approximately $75 \%$. In addition to early follow-up angiography, the distinction between RCVS and PACNS is possible with thorough clinical assessment including careful history and CSF examination. 
At the present time the evidence for treatment in RCVS is limited to observational studies. The offending medications should be discontinued in patients with secondary RCVS. Bed rest is very useful in reducing headache severity. Nimodipine has been reported to ameliorate the headache in $64-83 \%$ of patients. $^{3} 817$ However, it showed no benefit over symptom control. Magnesium sulfate has also been tried with favourable outcome. ${ }^{18} 19$ Steroid, although previously regarded to be a potential treatment, recent study has shown poor outcome on those who received steroids for the treatment of RCVS. ${ }^{4}$

There was no recurrence in the French cohort, however, the study that was conducted in Taiwan demonstrated $8 \%$ recurrence rate over the mean 25 months follow-up. ${ }^{3} 20$

The prognosis is uncertain, however, in most of the patients RCVS appears to be self-limiting. Stroke is the major determinant of persistent morbidity. Studies have reported between $7 \%$ and $50 \%$ risk of stroke in patients with RCVS. ${ }^{21-23}$

\section{Learning points}

- The most important clinical hallmark of reversible cerebral vasoconstriction syndrome (RCVS) is thunderclap headache.

- MR angiography is the first-line investigation given the invasiveness of the catheter angiogram and the high risk of transient neurological deficits $(9 \%)$ that complicates the conventional angiography.

- In view of the high risk of stroke in RCVS (up to 50\%), RCVS should be considered in the differential of cryptogenic stroke particularly if the stroke is accompanied by headache.

- Systematic imaging of cervical arteries is necessary in patients with RCVS.

- Differentiation between RCVS and primary angiitis of the central nervous system, although they share the same angiographic appearance, is possible through detailed history and cerebrospinal fluid analysis and more importantly follow-up angiography. This would help to avoid invasive test such as brain biopsy and steroid therapy which has shown to be detrimental in patients with RCVS.

Contributors TMA was the major contributor in the study of this case. MS and NOA helped with editing the manuscript. MO'C acted as a senior author and she was the consultant responsible for the patient care.

Competing interests None.

\section{Patient consent Obtained.}

Provenance and peer review Not commissioned; externally peer reviewed.

\section{REFERENCES}

1 Hajj-Ali RA, Furlan A, Abou-Chebel A, et al. Benign angiopathy of the central nervous system: cohort of 16 patients with clinical course and long-term followup. Arthritis Rheum 2002;47:662-9.

2 Calabrese LH, Dodick DW, Schwedt TJ, et al. Narrative review: reversible cerebral vasoconstriction syndromes. Ann Intern Med 2007;146:34-44.

3 Ducros A, Boukobza M, Porcher $R$, et al. The clinical and radiological spectrum of reversible cerebral vasoconstriction syndrome. A prospective series of 67 patients. Brain 2007:130:3091-101.

4 Singhal AB, Hajj-Ali RA, Topcuoglu MA, et al. Reversible cerebral vasoconstriction syndromes: analysis of 139 cases. Arch Neurol 2011;68:1005-12.

5 Liu HY, Fuh JL, Lirng JF, et al. Three paediatric patients with reversible cerebral vasoconstriction syndromes. Cephalalgia 2010;30:354-9.

6 Kirton A, Diggle J, Hu W, et al. A pediatric case of reversible segmental cerebral vasoconstriction. Can J Neurol Sci 2006;33:250-3.

7 Ghosh PS, Rothner AD, Zahka KG, et al. Reversible cerebral vasoconstriction syndrome: a rare entity in children presenting with thunderclap headache. J Child Neurol 2011;26:1580-4.

8 Chen SP, Fuh JL, Lirng JF, et al. Recurrent primary thunderclap headache and benign CNS angiopathy: spectra of the same disorder? Neurology 2006;67:2164-9.

9 Dodick DW. Thunderclap headache. J Neurol Neurosurg Psychiatry 2002;72:6-11.

10 Chen SP, Fuh JL, Chang FC, et al. Transcranial color Doppler study for reversible cerebral vasoconstriction syndromes. Ann Neurol 2008;63:751-7.

11 Aralasmak A, Akyuz M, Ozkaynak C, et al. CT angiography and perfusion imaging in patients with subarachnoid hemorrhage: correlation of vasospasm to perfusion abnormality. Neuroradiology 2009;51:85-93.

12 Ducros A, Fiedler U, Stapf C, et al. Hemorrhagic complications in reversible cerebral vasoconstriction syndrome are more frequent in women and in migrainers. Cephalalgia 2009;29:153.

13 Mawet J, Boukobza M, Franc J, et al. Reversible cerebral vasoconstriction syndrome and cervical artery dissection in 20 patients. Neurology 2013;81:821-4.

14 Duna GF, Calabrese LH. Limitations of invasive modalities in the diagnosis of primary angiitis of the central nervous system. J Rheumatol 1995;22:662e7.

15 Nadeau SE. Diagnostic approach to central and peripheral nervous system vasculitis. Neurol Clin 1997;15:759e77.

16 Younger DS. Vasculitis of the nervous system. Curr Opin Neurol 2004;17:317-36.

17 Lu SR, Liao YC, Fuh JL, et al. Nimodipine for treatment of primary thunderclap headache. Neurology 2004;62:1414-16.

18 Chik Y, Hoesch RE, Lazaridis $C$, et al. A case of postpartum cerebral angiopathy with subarachnoid hemorrhage. Nat Rev Neurol 2009;5:512-16.

19 Singhal AB. Postpartum angiopathy with reversible posterior leukoencephalopathy. Arch Neurol 2004;61:411-16.

20 Chen SP, Fuh JL, Wang SJ, et al. Magnetic resonance angiography study in reversible cerebral vasoconstriction syndromes. Ann Neurol 2010;67:648-56.

21 Singhal AB. Cerebral vasoconstriction syndromes. Top Stroke Rehabil 2004:11:1-6.

22 Valenca MM, Andrade-Valenca LP, Bordini CA, et al. Thunderclap headache attributed to reversible cerebral vasoconstriction: view and review. J Headache Pain 2008:9:277-88

23 Ducros A. Reversible cerebral vasoconstriction syndrome. Lancet Neurol 2012;11:906-17.

Copyright 2014 BMJ Publishing Group. All rights reserved. For permission to reuse any of this content visit

http://group.bmj.com/group/rights-licensing/permissions.

BMJ Case Report Fellows may re-use this article for personal use and teaching without any further permission.

Become a Fellow of BMJ Case Reports today and you can:

- Submit as many cases as you like

- Enjoy fast sympathetic peer review and rapid publication of accepted articles

- Access all the published articles

- Re-use any of the published material for personal use and teaching without further permission

For information on Institutional Fellowships contact consortiasales@bmjgroup.com

Visit casereports.bmj.com for more articles like this and to become a Fellow 